\title{
Water, water everywhere but not a drop to drink?
}

\author{
A. J. Smith, ${ }^{1}$ J. Hood, ${ }^{2}$ J. Bagg, ${ }^{3}$ and F. T. Burke, ${ }^{4}$
}

\begin{abstract}
Biofilms are emerging as an increasing problem as medical technology advances. Dental practice is no exception and interest in the role of biofilms within dental units as a possible source of cross-infection is intensifying. It is difficult to quantitate the risks associated with aerosolised bacteria for the majority of patients seen in general practice. However, it seems prudent to eliminate this source of infection during treatment of compromised patients. This article attempts to provide a brief overview of current concepts and problems in this area of infection control.
\end{abstract}

Dental unit water lines are an integral part of dental surgery equipment, supplying water as a coolant, primarily for air turbines and ultrasonic scalers. This operation inevitably leads to a fine spray which is then inhaled by both the patient and the dental staff. The large volumes of water produced are mostly removed by high volume aspiration although some is almost certainly swallowed by the patient. Several reports ${ }^{1-7}$ and our own unpublished observations have suggested that microbial contamination of dental unit water lines is a common event. This article discusses the possible implications of these findings.

The water quality regulations provide a legal definition of the term 'wholesomeness' when applied to potable water and include a number of chemical and microbiological parameters. ${ }^{8}$ Water-borne pathogens such as Legionella species and coliforms, eg E. coli, should always be absent from potable water supplies. The usual standard for the number of colony forming

\footnotetext{
${ }^{1}$ Lecturer \& Honorary Specialist Registrar in Oral Microbiology, ${ }^{3}$ Senior Lecturer \& Honorary Consultant in Oral Microbiology, Infection Research Group, Glasgow Dental Hospital \& School, 378 Sauchiehall Street, Glasgow G2 3JZ; ${ }^{2}$ Consultant Microbiologist, Bacteriology Department, Glasgow Royal Infirmary, Castle Street, Glasgow G4 OSF; ${ }^{4}$ Professor of Primary Dental Care, Dental Primary Care Unit, Glasgow Dental Hospital \& School, 378 Sauchiehall Street, Glasgow G2 3JZ REFEREED PAPER

Received 12.02.98; accepted 08.07.98

(C) British Dental Journal 1999; 186: 12-14
}

units (cfu) accepted in potable water is less than $10 \mathrm{cfu} / \mathrm{ml}$ at $37^{\circ} \mathrm{C}$ (or less than $100 \mathrm{cfu} / \mathrm{ml}$ at $\left.22^{\circ} \mathrm{C}\right) .8$

It has been known for more than 30 years that water from dental lines can be heavily contaminated with microorganisms. ${ }^{9}$ These findings of high levels of

The source of bacterial contamination within the dental unit water supply is thought to be because of

\section{microcolonies of} proliferating bacteria, fungi and protozoa on the inner surface of the water lines

microbial contamination, including more recently Legionella species, have been confirmed in general practice and hospital units in our own unpublished studies and by other workers. ${ }^{1-7}$ One of the major concerns is contamination of the water supply with Legionella species, in particular L. pneumophilia, the causative agent of Legionella pneumonia (Legionnaires' disease and non- pneumonic legionellosis (Pontiac fever)). Transmission of Legionellae to humans occurs when water containing the bacterium is aerosolised in droplets and inhaled. The risk of infection depends not only on the size and amount of the inhaled inoculum, but also on the susceptibility of the individual host. It has been suggested that the presence of Legionella species within dental line water may contribute to lower respiratory tract infections among dental personnel. ${ }^{10}$ It has been reported that dental staff have a higher prevalence of Legionella antibodies compared to the general public, ${ }^{11-13}$ suggesting that aerosols generated by dental equipment are a possible source of infection. This hypothesis may be supported by the recent case of a California dentist who died from Legionellosis. Subsequent investigations showed high levels of the same Legionella species from his dental units ${ }^{1}$ although molecular confirmation of source and infecting strain was lacking.

\section{Biofilms}

The source of bacterial contamination within the dental unit water supply is thought to be because of microcolonies of proliferating bacteria, fungi and pro-

\section{In brief}

- A review of the clinical implications of microbial contamination of dental unit water lines

- Highlights the inevitable failure of the chemical disinfection of dental unit water lines

- In the absence of new independent research, we advise that the BDA guidelines are followed to reduce the clinical implications of microbial contamination of dental unit water lines

- The solutions to the problem of microbial contamination in dental unit water lines lies in closer links between dental unit manufacturers, dentists and microbiologists to redesign the water supply lines to discourage biofilm development 
tozoa on the inner surface of the water lines. The organisms are embedded in a matrix of extracellular polymeric substances forming a biofilm. Biofilms are important because they protect organisms from the effects of heat and chemicals thus reducing their susceptibility to disinfection processes. The contact time required to produce a particular level of killing of organisms in the biofilm by chlorine may be hundreds or even thousands of times greater than that required to produce an equivalent kill for the organisms suspended in water. Thus, it is possible for organisms in biofilms to survive and grow even when the water contains residual chlorine at the concentrations employed in drinking water. This reduction in disinfection efficiency is caused by several factors inherent in the structure of the biofilm including reduced penetration, absorption or changes in bacterial structure. Disinfection failures may occur through neglect of this particular facet of infection control.

There have been several attempts to address this problem including autoclaving of handpieces, handpiece replacement between patients, flushing of the unit prior to use, 'anti-contamination' devices to prevent retrograde aspiration of oral secretions into the water supply line, connection to a separate water supply (eg connection to bottles of distilled water), chemical disinfection of waterlines, ultra-violet radiation disinfection and the use of inline water filters. These have been developed and implemented in many dental practices. ${ }^{3,10,14-16}$ The most commonly used procedure of flushing the handpiece with water prior to use may lower bacterial counts ${ }^{6,17}$ but high levels of microbial contamination can still persist. 6,17,18 Nevertheless, the British Dental Association (BDA) ${ }^{19}$ and Centers for Disease Control (CDC) ${ }^{20}$ recommend that all water lines should be allowed to run and discharge water for several minutes at the beginning of each day and for a shorter interval between patient appointments. Research to date suggests that which ever method is used, microbial recolonisation of the waterline is inevitable and repeat disinfecting treatments are necessary. We suspect that this is mainly because of the complex design of dental chair equipment, resulting in the stagnation of water within the equipment lines where bacteria, including Legionella species could proliferate within a biofilm. $^{2}$

\section{A public health problem?}

While many investigations have confirmed the types of microbial contamination that can accumulate in modern dental equipment, ${ }^{21}$ evidence is lacking that links this to a major public health problem. There may be several reasons for this. Most of the organisms charac-

\section{Non-pneumonic} Legionellosis of the Pontiac fever type may occur in dental personnel or their patients and cause symptoms clinically indistinguishable from other flu-like episodes

terised from contaminated dental and medical water sources are opportunistic pathogens with low virulence potentials and probably cause no problems when immuno-competent hosts are exposed to them. Secondly, the incidence of legionella community acquired pneumonia varies from $2-15 \%$ of all community acquired pneumonias that require hospitalisation. ${ }^{22}$ The sources of most cases of community-acquired pneumonic legionellosis are never iden- tified, ${ }^{23-25}$ therefore dental exposure may represent an unrecognised element in the history of previous cases. Furthermore, non-pneumonic Legionellosis of the Pontiac fever type may occur in dental personnel or their patients and cause symptoms clinically indistinguishable from other flu-like episodes.

\section{More research needed}

Therefore, the implications of heavily contaminated water from dental units are not fully understood and very little research has been undertaken in this area. Workers have reported that extended exposure to aerosols from dental handpieces, air/water syringes and ultrasonic scalers may have been responsible for significantly elevated antibody titres against Legionella species in dental clinic personnel, when compared with known negative controls. ${ }^{11,13}$ In view of the extent of exposure of patients and staff to Legionella species from a dental source it is surprising that no definitive clinical associations with community acquired pneumonia have emerged thus far. ${ }^{2,26}$ Where contaminated water, eg potable or nebulised water, has been involved as a source of infection, such as in hospitals, most patients infected were known to be immunosuppressed. With a greater proportion of the general public living longer, conditions known to compromise host resistance will become more common in the community and in return this problem may become more acute in general dental practice.

\section{Conclusion}

Various studies have identified significant microbial contamination of dental unit waters, including Legionella species. At present, there is little epidemiological evidence that this constitutes a significant risk of infection, though collecting the appropriate data is difficult. Among immunocompromised individuals there is undoubtedly a potential for infection by this route. Therefore, every effort should be made to ensure that potable 
quality water emerges from dental unit handpieces. This should firstly involve co-operation between dental unit manufacturers, dental practitioners and microbiologists to produce equipment that does not encourage the build up of biofilms. The importance of the engineering and design issues are highlighted in a recent publication which indicates that certain models of dental units are

\section{It has been suggested that the presence of Legionella species within dental line water may contribute to lower respiratory tract infections among dental personnel}

more prone to contamination with Legionella species. ${ }^{27}$ Secondly, a reasonable protocol for disinfecting and monitoring the water supply in busy dental practices is required urgently, so water used for dental patient treatment satisfies accepted, safe public health standards. In view of the paucity of reliable data on disinfection of dental units, we feel it necessary to stand by the BDA and CDC statements ${ }^{19,20}$ on the control of microbial contamination in dental unit water lines. However, we trust as a result of ongoing research and evaluation of novel decontamination regimes, firmer recom- mendations should be possible in the near future.

1 Atlas R M, Williams J F, Huntington M-K. Legionella contamination of dental unit waters. Appl Environ Microbiol 1995; 61: 1208-1213.

2 Pankhurst C L, Philpott-Howard J N. The microbiological quality of water in dental chair units. J Hosp Infect 1993; 23: 167-174.

3 Pankhurst C L, Philpott-Howard J N, Hewitt J, Casewell M W. The efficacy of chlorination and filtration in the control and erradication of Legionella from dental chair water systems. J Hosp Infect 1990; 16: 9-18.

4 Whitehouse R L S, Peters G, Lindte J, Lilge C. Influence of biofilms on microbial contamination in dental unit water. J Dent 1991; 19: 290-295.

5 Williams H N, Kelley J, Folineo D, Williams G C, Hawley C L, Sibiski J. Assessing microbial contamination in clean water dental units and compliance with disinfection protocol. J Am Dent Assoc 1994; 125: 1205-1211.

6 Williams J F, Johnston A M, Johnson B, Huntington M K, Mackenzie C D Microbial contamination of dental unit water lines: prevalence, intensity and microbial characteristics. J Am Dent Assoc 1993; 124: 59-65.

7 Williams H N, Paszko-Kolva C, Shahamat M, Palmer C, Pettis C, Kelley T. Molecular techniques reveal high prevalence of Legionella in dental units. JADA 1996; 127: 1188-1193.

8 The microbiology of water 1994. Part 1 drinking water. HMSO publications.

9 Blake GC. The incidence and control of bacterial infection of dental units and ultrasonic scalers. Br Dent J 1963; 115: 413-416.

10 Paszko-Kovla C. Risk of infection from dental handpieces. ASM News 1991; 57: 287.

11 Fotos P G, Westfall H N, Synder I S, Miller R W, Mutchler BM. Prevalence of Legionella specific IgG and IgM antibody in a dental clinic population. J Dent Res 1985; 64: 1328-1385.

12 Paszko-Kolva C C, Shahamat M, Keiser J, Colwell R R. Prevalence of antibodies against Legionella species in healthy and patient populations. In JM Barbaree, RF Brieman and AP Dufour (eds) Legionella: current status and emerging prospectives. pp24-26. Washington DC: American Society for Microbiology, 1993.
13 Reinthaler F F, Mascher F, Stunzer D. Serological examination for antibodies against Legionella species in dental personnel. J Dent Res 1988; 67: 942-943.

14 Martin M V. The significance of bacterial contamination of dental unit water systems. Br Dent J 1987; 163: 152-154.

15 Scheid R C, Kim C K, Bright J S, Whitely M $\mathrm{S}$, Rosen S. Reduction of microbes in handpieces by flushing before use. J Am Dent Assoc 1982; 105: 658-660.

16 Scheid R C, Rosen S, Beck F M. Reduction of CFUs in high-speed handpiece water lines over time. Clin Prev Dent 1990; 12: 9-12.

17 Karpay R I, Puttaiah R, Mills S E, Plamondon T J, Dove S B, Levine U. Efficacy of flushing dental units for different time periods. J Dent Res 1997; 76: (abstract) 3366.

18 Gross A, Devine M J, Cutright D E. Microbial contamination of dental units and ultrasonic scalers. J Periodontol 1976; 47: 670-673.

19 British Dental Association. Infection Control in Dentistry: Advice Sheet 1996; A12: 7.

20 Centers for Disease Control. Recommended infection control practices for dentistry. MMWR 1993; 42: 1-12.

21 Molinari J A. Practical infection control for the 1990's. Applying science to government regu-lations. J Am Dent Assoc 1994; 125: 1189-1197.

22 Muder R R, Yu V L, Fang G D. Community acquired legionnaires disease. Semin Respir Infect 1989; 4: 32-29.

23 Anonymous. Legionnaires disease in England and Wales, 1997. Com Dis Rep Weekly 1997; 7: 321-324.

24 Jospeh C A, Harrison T G, Ilijic-Car D, Bartlett C L R. Legionnaires disease surveillance: England and Wales, 1996. CDR Review 1997; 7: 153-159.

25 Oppenheim B A, Sefton A M, Gill O N, et al. Widespread Legionella pneumophilia contamination of dental stations in a dental school without apparent human infection. Epidemiol Infect 1987; 99: 159-166.

26 Stout J E, Yu V L, Muraca J, Joly N, Troup N, Tompkins L S. Potable water as a cause of spo-radic cases of community-acquired Legionaires disease. N Engl J Med 1992; 326: 151-155.

27 Challacombe S J, Fernandes L L. Detecting Legionella pneumophila in water systems: A comparison of various dental units. J Am Dent Assoc 1995; 126: 603-608. 